\title{
Faktor Yang Berhubungan dengan Kesiapan Psikologis Ibu Hamil Trimester III dalam Menghadapi Persalinan
}

\author{
Factors Related to Psychological Readiness of Pregnant Trimester III Mother in \\ Facing Labor
}

\author{
Lisa Elvina *1, Raudhatun Nuzul ZA ${ }^{2}$, Eva Rosdiana ${ }^{3}$ \\ ${ }^{1,2,3}$ Program Studi D-IV Bidan Pendidik Fakultas Ilmu Kesehatan Universitas Ubudiyah Indonesia, Jl. Alue Naga \\ Desa Tibang Kota Banda Aceh \\ *Korespondensi Penulis: lisaelvina@yahoo.com
}

\begin{abstract}
Abstrak
Faktor psikologis yang berpengaruh dalam kehamilan dapat berasal dari dalam diri ibu hamil (internal) dan dapat juga berasal dari faktor luar diri ibu hamil. Tujuan penelitian ini untuk mengetahui analisis faktor-faktor yang berhubungan dengan kesiapan psikologis ibu hamil trimester III dalam menghadapi persalinan. Penelitian ini bersifat analitik dengan pendekatan cross sectional. Populasi dalam penelitian ini ibu hamil trimester III sebanyak 57 responden. Tehnik pengambilan sampel dilakukan secara total populasi. Jumlah sampel adalah 57 orang. Analisa data dilakukan dengan menggunakan uji chi-square dengan batas kemaknaan 95\% $(P \leq 0,05)$. Kesimpulan penelitian ini yaitu ada hubungan informasi dengan kesiapan psikologis ibu hamil $(P$-value $=0,016)$, ada hubungan dukungan suami $(P$-value $=0,009)$, ada hubungan pengalaman $(P$-value $=0,037)$ dengan kesiapan psikologis ibu hamil trimester III. Diharapkan bagi tenaga kesehatan agar memperhatikan psikologis ibu hamil trimester III yang akan menghadapi persalinan dengan memberikan asuhan kehamilan yang komprehensif. Selain itu tenaga kesehatan khususnya bidan dapat terus memberikan dukungan sehingga ibu hamil senang karena mendapat perhatian.
\end{abstract}

Kata kunci : kesiapan psikologis, informasi, dukungan suami, pengalaman

\begin{abstract}
Psychological factors that influence pregnancy can come from within the pregnant woman (internal) and can also come from factors outside of the pregnant woman. The purpose of this study was to determine the analysis of factors related to the psychological readiness of third trimester pregnant women in facing labor. This research is analytical with cross sectional approach. The population in this study were trimester III pregnant women as many as 57 respondents. The sampling technique is carried out in a total population. The number of samples is 57 people. Data analysis was performed using the chi-square test with a significance limit of $95 \%(P \leq 0.05)$. The conclusion of this study is that there is a relationship of information with psychological preparedness of pregnant women $(P$-value $=0.016)$, there is a relationship of husband support $(P$-value $=0.009)$, experience relationship $(P$-value $=$ $0.037)$ with psychological readiness of third trimester pregnant women. It is expected that health workers will pay attention to the psychology of third trimester pregnant women who will face childbirth by providing comprehensive pregnancy care. In addition, health workers
\end{abstract}


especially midwives can continue to provide support so that pregnant women are happy because they receive attention

Keywords: Psychological Readiness, Information, Husband Support, Experience

\section{PENDAHULUAN}

World Health Organization(WHO) mencatat, sekitar $13 \%$ ibu hamil mengalami gangguan kecemasan, umumnya depresi. Di negara-negara berkembang, persentasenya bahkan bisa mencapai 19,8\%. Sejalan dengan temuan penelitian Honikman, WHO juga menyatakan bahwa depresi yang mengarahkan pada ide bunuh diri pada perempuan rentan terjadi setelah kelahiran bayinya.Tidak cuma ide bunuh diri saja yang timbul sebagai efek depresi pasca- melahirkan. Kesulitan merespons kebutuhan bayi pun menjadi tanda lain seorang ibu mengalami depresi (Kirnandita, 2016).

Indonesia terdapat 373.000.000 ibu hamil sedangkan yang mengalami kecemasan dalam menghadapi proses persalinan ada sebanyak 107.000.000 ibu hamil (28,7\%) (Arifin, 2015). Penelitian yang dilakukan Lee Lam Marie, Chong, Chui dan Fong dalam jurnal Yuliasari (2016), menunjukkan lebih dari setengah atau 54\% dan lebih dari sepertiga atau $37 \%$ dari perempuan memiliki kecemasan saat sedang hamil dan gejala depresi, kecemasan lebih umum terjadi saat kehamilan hingga menjelang persalinan. Lebih dari $20 \%$ wanita hamil melaporkan ketakutan dan 6\% menggambarkan rasa takut yang melumpuhkan. $13 \%$ dari seluruh wanita yang tidak hamil melaporkan rasa takut akan persalinan sehingga cukup untuk menunda atau menghindari kehamilan (Yuliasari, 2016).

Selama kehamilan kebanyakan wanita mengalami perubahan psikologis dan emosional. Perubahan fisik dan emosional yang kompleks, memerlukan adaptasi terhadap penyesuaian pola hidup dengan proses kehamilan yang terjadi. Menurut hasil penelitian Astria (2009)

sejak saat hamil, ibu sudah mengalami kecemasan.Kecemasan meningkat menjelang persalinan terutama pada trimester III. Pada ibu hamil trimester III umumnya mengalami kecemasan dalam menghadapi persalinan $(52,5 \%)$ dan sisanya tidak mengalami kecemasan (47,5\%) (Istikhomah, 2015).

Menurut data Profil Dinas Kesehatan Aceh tahun 2016, bahwa jumlah seluruh ibu hamil sebesar 105.409 jiwa, sedangkan angka kematian ibu (AKI) di Provinsi Aceh tahun 2013 sebesar 190/100.000 kelahiran hidup (Dinkes Provinsi Aceh, 2016). Sedangkan data yang diperoleh dari dinkes Pidie, jumlah kunjungan ibu hamil K1 8.728 (85\%), dan K4 73.31 
(72\%) (Dinkes Pidie, 2016).

Reaksi psikologis dalam kehamilan yang terjadi yaitu reaksi cemas, gangguan ini ditandai dengan rasa cemas dan kebutuhan yang berlebihan terutama sekali pada hal-hal yang masih tergolong wajar. Reaksi panik juga timbul dalam periode yang relatif singkat tanpa sebab yang jelas, reaksi obsesif komulatif selalu timbul perasaan, rangsangan, atau pikiran. Reaksi ini dapat terjadi pada ibu yang kurang mendapat perhatian dari suami atau keluarga yang lain (Bahiyatun 2014).

Faktor psikologis yang berpengaruh dalam kehamilan dapat berasal dari dalam diri ibu hamil (internal) dan dapat juga berasal dari faktor luar diri ibu hamil.Faktor prikologis yang mempengaruhi kehamilan berasal dari dalam diri ibu dapat berupa latar belakang kepribadian ibu dan pengaruh perubahan hormonal yang terjadi selama kehamilan.Faktor psikologis yang berasal dari luar diri ibu dapat berupa pengalaman Ibu, kecemasan dan gangguan emosi, dukungan keluarga, dan dukungan suami (Pradyani, 2015).

Data yang diperoleh dari BPM Nurul Husna, jumlah kunjungan ibu hamil tahun 2017 mencapai 376 orang.sedangkan jumlah ibu hamil trimester III per bulan rat-rata sebanyak 56 orang. (14,9\%), jumlah ibu hamil bulan Juni-Juli sebanyak 57 orang (18, 3\%). Berdasarkan hasil wawancara pada 8 orang ibu hamil trimester III, 5 orang $(62,5 \%)$ ibu belum ada kesiapan dalam menghadapi persalinan karena ini merupakan proses kelahiran pertama kali sehingga belum ada pengalaman, dan ibu yang hamil kedua atau ketiga ada yang mengalami trauma saat persalinan sehingga sangat cemas menghadapi persalinan nanti. Kecemasan ibu bertambah jika suami sedang diluar kota dan belum ada biaya untuk persiapan persalinan sehingga ibu sangat membutuhkan keberadaan suaminya saat usia kehamilan sudah hampir mendekati persalinan. Akibat dari ketidaksiapan, ibu dapat mengalami depresi dan trauma untuk hamil dan melahirkan kembali, karena rasa takut atau cemas yang dirasakansehingga dukungan suami atau keluarga sangat dibutuhkan. Sementara 3 orang $(37,5 \%)$ ibu persalinan yang pertama sehingga ibu sudah memiliki pengalaman, dan persalinan yang lalu juga dilalui tanpa ada masalah. Akan tetapi sedikit rasa cemas juga dirasakan ibu jika memikirkan sakitnya proses melahirkan secara normal.

\section{METODE PENELITIAN}

Penelitian ini menggunakan metode analitik dengan pendekatan Cross sectional. Penelitian ini telah dilakukan pada tanggal 12 April sampai 4 Agustus 2018 di BPM Nurul 
Husna Kabupaten Pidieyang berkunjung ke Bidan Praktek Mandiri Nurul Husna pada bulan Juni-Juli sebanyak 57 responden.Tehnik pengambilan sampel dilakukan secara Total Populasi. Analisa data dilakukan dengan menggunakan uji Chi-square dengan batas kemaknaan $95 \%(\mathrm{P}<0,05)$.

\section{HASIL DAN PEMBAHASAN}

\section{Analisa Univariat}

Tabel 1. Distribusi Frekuensi Faktor- faktor yang Berhubungan Dengan Kesiapan Psikologis Ibu Hamil Trimester III Dalam Menghadapi Persalinan

\begin{tabular}{lcc}
\hline \multicolumn{1}{c}{ Kategori } & f & \% \\
\hline Kesiapan Psikologis & & \\
$\quad$ Siap & 32 & 56,1 \\
$\quad$ Tidak Siap & 25 & 43,9 \\
\hline Total & 57 & 100 \\
\hline Informasi & & \\
$\quad$ Pernah & 25 & 43,9 \\
$\quad$ Tidak Pernah & 32 & 56,1 \\
\hline Total & 57 & 100 \\
\hline Dukungan Suami & & \\
$\quad$ Mendukung & 39 & 68,4 \\
$\quad$ Tidak Mendukung & 18 & 31,6 \\
\hline Total & 57 & 100 \\
\hline Pengalaman & & \\
$\quad$ Pernah & 32 & 56,1 \\
$\quad$ Tidak Pernah & 25 & 43,9 \\
\hline Total & 57 & 100 \\
\hline
\end{tabular}

\section{Analisa Bivariat}

a. Hubungan Informasi Dengan Kesiapan Psikologis

Tabel 2. Hubungan Informasi Dengan Kesiapan Psikologis Ibu Hamil Trimester III Dalam Menghadapi Persalinan di Bidan Praktek Mandiri Nurul Husna Kabupaten Pidie Tahun 2018

\begin{tabular}{|c|c|c|c|c|c|c|c|}
\hline \multirow{3}{*}{ Informasi } & \multicolumn{4}{|c|}{$\begin{array}{c}\text { Kesiapan Psikologis Ibu } \\
\text { Hamil Trimester III }\end{array}$} & \multirow{2}{*}{\multicolumn{2}{|c|}{ Total }} & \multirow[t]{3}{*}{$\begin{array}{c}P \\
\text { Value }\end{array}$} \\
\hline & \multicolumn{2}{|c|}{ Siap } & \multicolumn{2}{|c|}{ Tidak } & & & \\
\hline & $\mathrm{n}$ & $\%$ & $\mathrm{n}$ & $\%$ & $\mathrm{n}$ & $\%$ & \\
\hline Pernah & 19 & 76 & 6 & 24 & 25 & 100 & 0016 \\
\hline Tidak Pernah & 13 & 40,6 & 19 & 59,4 & 32 & 100 & \\
\hline
\end{tabular}

Berdasarkan tabel 2 di atas menunjukkan bahwa dari 32 responden yang tidak pernah mendapatkan informasi ada 59,4\% psikologis ibu hamil yang tidak siap dalam menghadapi 
persalinan. Hasil analisa statistik dengan chi square test menunjukkan ada hubungan informasi dengan kesiapan psikologis ibu hamil dimana nilai $P$-value $=0,016(P \leq 0,05)$, hipotesa yang menyebutkan ada hubungan informasi dengan kesiapan psikologis ibu hamil trimester III dalam menghadapi persalinan di BPM Nurul Husna Kabupaten Pidie terbukti.

b. Hubungan Dukungan Suami Dengan Kesiapan Psikologis

Tabel 3. Hubungan Dukungan Suami dengan Kesiapan Psikologis Ibu Hamil Trimester III dalam Menghadapi Persalinan di Bidan Praktek Mandiri Nurul Husna Kabupaten Pidie Tahun 2018

\begin{tabular}{|c|c|c|c|c|c|c|c|}
\hline \multirow[t]{3}{*}{ Dukungan Suami } & \multicolumn{4}{|c|}{$\begin{array}{c}\text { Kesiapan Psikologis Ibu Hamil } \\
\text { Trimester III }\end{array}$} & \multirow{2}{*}{\multicolumn{2}{|c|}{ Total }} & \multirow[t]{3}{*}{$\begin{array}{c}P \\
\text { Value }\end{array}$} \\
\hline & \multicolumn{2}{|c|}{ Siap } & \multicolumn{2}{|c|}{ Tidak } & & & \\
\hline & $\mathrm{n}$ & $\%$ & $\mathrm{n}$ & $\%$ & $\mathrm{n}$ & $\%$ & \\
\hline Mendukung & 25 & 64,1 & 14 & 35,9 & 39 & 100 & \\
\hline Tidak Mendukung & 7 & 38,9 & 11 & 61,1 & 18 & 100 & 1,009 \\
\hline
\end{tabular}

Berdasarkan tabel 3 di atas menunjukkan bahwa dari 39 responden yang mendapat dukungan suami ada 35,9\% psikologis ibu hamil yang tidak siap dalam menghadapi persalinan. Hasil analisa statistik dengan chi square test menunjukkan ada hubungandukungan suami dengan kesiapan psikologis ibu hamil dimana nilai $P$-value $=0,009$ $(P \leq 0,05)$, hipotesa yang menyebutkanada hubungan dukungan suami dengan kesiapan psikologisibu hamil trimester III dalam menghadapi persalinan di BPM Nurul Husna Kabupaten Pidie terbukti.

c. Hubungan Pengalaman dengan Kesiapan Psikologis

Tabel 4. Hubungan Pengalaman dengan Kesiapan Psikologis Ibu Hamil Trimester III dalam Menghadapi Persalinan di Bidan Praktek Mandiri Nurul Husna Kabupaten Pidie Tahun 2018

\begin{tabular}{|c|c|c|c|c|c|c|c|}
\hline \multirow{3}{*}{ Pengalaman } & \multicolumn{4}{|c|}{$\begin{array}{c}\text { Kesiapan Psikologis Ibu Hamil } \\
\text { Trimester III }\end{array}$} & \multirow{2}{*}{\multicolumn{2}{|c|}{ Total }} & \multirow[t]{3}{*}{$\begin{array}{c}P \\
\text { Value }\end{array}$} \\
\hline & \multicolumn{2}{|c|}{ Siap } & \multicolumn{2}{|c|}{ Tidak } & & & \\
\hline & $\mathrm{n}$ & $\%$ & $\mathrm{n}$ & $\%$ & $\mathrm{n}$ & $\%$ & \\
\hline Pernah & 22 & 68,8 & 10 & 31,2 & 32 & 100 & 0 \\
\hline Tidak Pernah & 10 & 40 & 15 & 60 & 25 & 100 & 0,031 \\
\hline
\end{tabular}

Berdasarkan tabel 4 di atas menunjukkan bahwa dari 32 responden yang pernah memiliki pengalaman ada $31,2 \%$. Hasil analisa statistik dengan chi square test menunjukkan 
ada hubunganpengalaman dengan kesiapan psikologis ibu hamil dimana nilai $P$-value $=0,037$ $(P \leq 0,05)$, hipotesa yang menyebutkanada hubunganpengalaman dengan kesiapan psikologisibu hamil trimester III dalam menghadapi persalinan di BPM Nurul Husna Kabupaten Pidie terbukti.

\section{Pembahasan}

Hasil penelitian ini menunjukkan bahwa dari 32 responden yang tidak pernah mendapatkan informasi ada 59,4\% psikologis ibu hamil yang tidak siap dalam menghadapi persalinan. Hasil analisa statistik dengan chi square test menunjukkan ada hubungan informasi dengan kesiapan psikologis ibu hamil dimana nilai $P$-value $=0,016(P \leq 0,05)$.

Hasil penelitian ini berbeda dengan penelitian yang dilakukan oleh Zamriati (2014), yang menunjukkan bahwa tidak ada hubungan yang signifikan informasi tentang kesiapan psikologis ibu hamil menjelang persalinan di poli KIA PKM Tuminting dengan nilai p-value $=0,064(\mathrm{p}>0,05)$.

Menurut teori Zamriati (2014), informasi merupakan salah satu faktor yang mempengaruhi tingkat pengetahuan seseorang, informasi tentang kesiapan psikologis saat persalinan dapat diperoleh melalui media cetak atau elektronik, internet, informasi dari petugas kesehatan, keluarga atau teman. Pengaruh media massa tidaklah sebesar pengaruh interaksi individu secara langsung, tetapi media massa memiliki pengaruh yang besar dalam proses pembentukan pengetahuan dan sikap. Terbatasnya bekal informasi ibu hamil tentang kesiapan psikologis menjadikan ibu hamil perlu mendapatkan perhatian dan pengarahan mengenai dampak dari psikologis ketidaksiapan ibu dalam menghadapi persalinan.

Menurut asumsi peneliti, informasi kesiapan psikologis ibu biasanya didapat dari tenaga kesehatan atau keluarga terdekat.Dari hasil penelitian menunjukkan sebagian responden tidak mendapat informasi khususnya tentang kesiapan psikologis ibu dalam menghadapi persalinan.Ibu yang tidak mendapatkan informasi psikologisnya tidak siap disebabkan karena faktor ketidaktahuan ibu mengenai tanda atau gejala jika terjadi gangguan psikologis.Padahal informasi tersebut penting diberikan kepada ibu trimester III agar lebih siap menjelang persalinan nanti.Sedangkan ibu yang tidak pernah mendaptkan inforomasi dan psikologisnya siap disebabkan karena adanya dorongan dan dukungan dari suami atau keluarga agar ibu tidak merasa cemas saat persalinan nanti. 
Hasil penelitian ini menunjukkan bahwa dari 39 responden yang mendapat dukungan keluarga ada 35,9\% psikologis ibu hamil yang tidak siap dalam menghadapi persalinan. Hasil analisa statistik dengan chi square test menunjukkan ada hubungan dukungan suami dengan kesiapan psikologis ibu hamil dimana nilai $P$-value $=0,009(P \leq 0,05)$.

Penelitian ini sesuai dengan penelitian yang dilakukan oleh Puspitasari (2014), yang menyebutkan bahwa ada hubungan peran suami dengan kesiapan ibu hamil trimester III dalam menghadapi persalinan di RB Rahayu Semarang dengan nilai $P$-value $=0,034$ yang berarti Ha diterima. Suami merupakan orang terdekat bagi ibu hamil, dan dukungan saat menjelang persalinan sangat dibutuhkan sehingga ibu merasa disayangi dan diperhatikan dan ibu lebih siap dalam menghadapi proses persalinan.

Teori yang dikemukakan oleh Handayani (2014), perhatian dan dukungan dari orangorang terdekat terutama suami sangat membantu dalam mengatasi kecemasan yang dialami ibu hamil karena perubahan-perubahan baik fisik maupun psikologis yang terjadi selama kehamilan. Dukungan suami akan meningkatkan kesejahteraan psikologis (psychologocal well being) dan kemampuan penyesuian diri melalui perasaan memiliki, peningkatan harga diri, pencegahan psikologis, pengurangan stres serta penyediaan sumber atau bantuan yang dibutuhkan selama kehamilan.

Menurut asumsi peneliti, berdasarkan hasil penelitian diperoleh bahwa sebagian besar responden mendapat dukungan dari suami. Ibu yang mendapat dukungan suami akan lebih siap psikologisnya karena disebabkan semakin tinggi dukungan dari orang sekitar terutama suami maka akan semakin rendah kecemasan menjelang kelahiran yang dialami oleh ibu hamil. Memberikan perhatian dan kasih sayang dapat mengurangi psikologis ibu, bentuk perhatian seperti menemani pemeriksaan kehamilan dan terus memberikan dukungan bahwa ibu dapat menjalani proses melahirkan dengan lancar dapat membuat ibu senang dan tidak depresi.

Hasil penelitian ini menunjukkan bahwa dari 32 responden yang pernah memiliki pengalaman ada $31,2 \%$ psikologis ibu hamil yang tidak siap dalam menghadapi persalinan. Hasil analisa statistik dengan chi square test menunjukkan ada hubunganpengalaman dengan kesiapan psikologis ibu hamil dimana nilai $P$-value $=0,037(P \leq 0,05)$.

Hasil penelitian ini sesuai dengan penelitian yang dilakukan oleh Zamriati (2014), yang menyebutkan bahwa ada hubungan pengalaman dengankecemasan ibu hamil menjelang persalinan di poli KIA PKM Tuminting dengan nilai $P$-value $=0,001$. Pengalaman buruk saat 
persalinan terdahulu akan membuat ibu trauma saat hamil atau bersalin kembali.

Teori yang dikemukakan oleh Zamriati (2014), pada ibu multigravida, kecemasan yang dialami biasanya kecemasan akan bayangan rasa sakit yang dideritanya dulu sewaktu melahirkan. Apalagi bagi ibu yang memiliki pengalaman kehamilan dengan resiko tinggi, tingkat kecemasannya juga pasti akan meningkat. Dimana kehamilan ini memiliki resiko tinggi baik selama kehamilan maupun pada proses persalinan. Pengalaman traumatis terbukti dapat mempengaruhi kecemasan ibu hamil dalam menghadapi persalinan.Oleh sebab itu proporsi kecemasan lebih banyak terjadi pada ibu hamil yang memiliki pengalaman trauma pada kehamilan sebelumnya.

Menurut asumsi peneliti, sebagian besar responden sudah pernah memiliki pengalaman tentang persalinan. Ibu yang memiliki pengalaman akan lebih siap psikologisnya dalam menghadapi persalinan karena sudah mengetahui dan merasakan bagaimana proses saat persalinan. Ibu yang memiliki pengalaman dan tidak siap psikologisnya karena ibu hamil atau bersalin pernah mengalami masalah, maka untuk kehamilan berikutnya biasanya ibu akan merasa takut atau cemas akan mengalami masalah yang sama lagi, bahkan tidak menutup kemungkinan ibu takut dan tidak ingin hamil lagi.

\section{KESIMPULAN}

Berdasarkan hasil penelitian dapat disimpulkan bahwa: Ada hubungan informasi dengan kesiapan psikologis ibu hamil dalam menghadapi persalinan dimana nilai $P$-value $=$ 0,016 $(P \leq 0,05)$, Ada hubungan dukungan suami dengan kesiapan psikologis ibu hamil dalam menghadapi persalinan dimana nilai $P$-value $=0,009(P \leq 0,05)$, Ada hubungan pengalaman dengan kesiapan psikologis ibu hamil dalam menghadapi persalinan dimana nilai $P$-value= $0,037(P \leq 0,05)$.

\section{SARAN}

Diharapkan bagi tenaga kesehatan dapat memperhatikan psikologis ibu hamil trimester III yang akan menghadapi persalinan dengan memberikan asuhan kehamilan yang komprehensif. Selain itu tenaga kesehatan khususnya bidan dapat terus memberikan dukungan sehingga ibu hamil senang karena mendapat perhatian. 


\section{DAFTAR PUSTAKA}

Adelina, (2014). Hubungan Dukungan Suami Dengan Tingkat Kecemasan Ibu Hamil Menghadapi Persalinan di Puskesmas Turi Sleman. Jurnal PDF.

Arikunto, (2014). Prosedur Penelitian, Suatu Pendekatan Praktik. Rineka Cipta, Jakarta.

Bahiyatun, (2014), Buku Ajar Bidan Psikologis Ibu dan Anak. EGC, Jakarta.

Darmayanti, I, P (2014).Asuhan Kebidanan Komprehensif pada Ibu Bersalin dan Bayi Baru Lahir. Deepublish, Yogyakarta

Kirnandita, (2016). Kesiapan Psikologis Ibu Hamil Dalam Menghadapi Persalinan Di Wilayah kerja Puskesmas Nanggalo Padang. Jurnal PDF.

Kusmiyati, Y, dkk.(2014), Perawatan Ibu Hamil. Fitramaya. Yogyakarta.

Maimunah, (2015). Faktor-faktor yang Berhubungan Dengan Kesiapan Persalinan di Puskesmas Banguntapan Yogyakarta. Jurnal PDF

Mochtar,R, (2014). Obstetri Fisiologi, Obstetri Patologi. EGC, Jakarta.

Notoatmodjo, S, (2014). Promosi Kesehatan Teori Dan Aplikasi. Rineka Cipta, Jakarta.

Prawirohardjo, (2014). Ilmu Kebidanan. YBP-SP, Jakarta.

Puspitasari, (2014). Hubungan Peran Suami Dengan Kesiapan Ibu Hamil Trimester III Dalam Menghadapi Persalinan di RB Rahayu Semarang. Jurnal PDF

Rukiyah, AY, (2014). Asuhan Kebidanan. Trans Info Media, Jakarta.

Saifuddin, (2014). Buku Panduan Praktis Pelayanan Kesehatan Maternal dan Neonatal. Jakarta: Yayasan Bina Pustaka Sarwono Prawirohardjo.

Sulistyawati, A, (2014). Asuhan Kebidanan Pada Masa Kehamilan. Salemba Medika, Jakarta. Sumarah. dkk. (2013). Perawatan Ibu Bersalin. EGC, Jakarta.

Susanti, (2015). Hubungan Pekerjaan dan Dukungan Suami terhdap Kesiapan Psikologis Ibu Hamil Trimester III Dalam Menghadapi Persalinan. Jurnal PDF.

Yuliasari, H, (2016). Kematangan Emosi dan Kecemasan Menghadapi Persalinan Pertama Pada Ibu Hamil di Puskesmas Putri Ayu Kota Jambi. Jurnal PDF.

Yulifah, R, (2014). Asuhan Kebidanan Komunitas. Salemba Medika, Jakarta.

Zamriati. (2014). Faktor-faktor yang Berhubungan Dengan Kecemasan Ibu Hamil Menjelang Persalinan di Poli KIA PKM Tuminting. Jurnal PDF. 